\title{
The application of management psychology in enterprise management now
}

\author{
Yanzhe ZHENG \\ SHEN ZHEN ET TECHNOLOGY CO. LTD, Shenzhen, Guangdong, China
}

\begin{abstract}
Research on management psychology behavior most is on the scope of individual psychology and modern management, is concerned with the problem of "human", psychological factors has become more important; sociology study both at the micro level of social interaction, to study the macro level social structure view, management psychology for groups of interpersonal relationship, role perception, group norms, values, organizational culture contents involved are derived from sociology. Anthropology of culture and environment interaction theory of management psychology development help, because in recent years the trend of internationalization has on the management of the new, namely how to manage employees from different cultural backgrounds, and the integration in specific organizational culture. The modern human resource management is also a subject that involves the organization and the cross domain of personality. Human resource management is the process of achieving the organization target through the acquisition, retention, termination, development and rational use of human resources in the organization. On the one hand, because enterprises are facing increasingly fierce competition, human resources costs continue to increase; on the other hand, the change of social, especially the trend of "globalization", of human resources are required higher and higher.
\end{abstract}

Keywords-Management psychology, Management activity, Heart activity, Behavior motivation

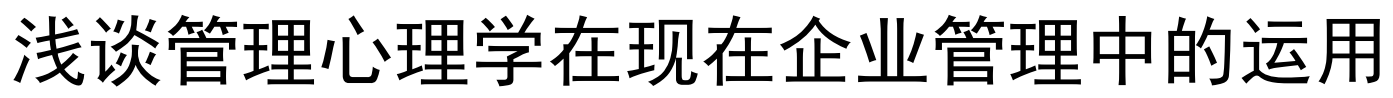

\author{
郑彦哲 \\ 深圳市尔泰科技有限公司，深圳，广东，中国
}

摘 要 管理心理学行为的研究绝大部分属于对个体心理学范畴, 而且现代管理中, 随着对 “人” 的问题的关注, 心理学的因素已 显得更加重要; 社会学既研究微观层面的社会互动, 也研究宏观层面的社会结构, 管理心理学中对于群体中的人际关系、角色知 觉、群体规范、价值观、组织文化等内容的涉及都来源于社会学。人类学中文化与环境的相互作用的理论对管理心理学的发展帮助 很大, 因为近年来国际化趋势产生了管理的新问题, 即如何管理不同文化背景的员工, 并使之整合于特定的组织文化中。现代人力 资源管理也是涉及组织与人格交叉领域的一门重要的学科。人力资源管理是通过获取、保留、终止、发展以及合理使用组织中人力 资源, 达成组织目标的过程。一方面由于企业面临的竞争日益激烈, 人力资源成本不断增加; 另一方面, 社会的变迁, 特别是 “全 球化”的趋势, 对人力资源的要求越来越高。

关键词 管理心理学, 管理活动, 心里活动, 行为激励

管理心理学之所以关注人的心理活动, 以人的心理 活动规律性为研究对象, 主要是基于这样几个原因: 首 先, “企业就是人”。企业要靠人来实现企业的目标。 即使是未来社会的管理, 最主要的仍然是对人的管理, 因此研究人的行为和心理规律, 以调动人的积极性, 必
然成为管理心理学的研究对象。其次, 人是企业的首要 资源。在现代企业管理中，企业资源包括人、财、物 等, 而人是最重要的资源, 随着现代科学技术的发展, 重视人的因素, 发挥人的主动精神, 挖掘人的潜在能力 显得更重要。再次，人是企业管理的主体。现代企业管 
理强调以人为中心, 科学技术越发展, 就越要重视人的 因素, 建立以人为中心的管理制度。因此, 管理心理学 着重研究人的心理活动的规律性, 将有助于在科学分析 的基础上, 了解人的心理规律, 采取科学的管理方法, 促使企业管理取得最佳的成绩。

下面, 我们重点讨论激励的五种方式: 目标激励, 期 望激励, 责任激励, 危机激励, 奖励激励。

\section{1. 人本管理思想的形成及其内涵}

在农业文明时代, 土地是第一生产要素, 谁拥有了大 片的土地, 谁就占据了生产链的最高端, 支配着生产过程 和产品的分配。工业革命将人类社会带入到了机器大生产 时代, 资本成为生产的关键因素。而随着第三次科技革命 的不断深入, 知识的爆炸式发展, 知识技术更新的周期越 来越短, 人作为知识的创造者和应用者, 成为现代化生产 中最具创造力, 最活跃, 最有革命性, 也是最有战略意义 的资源。可以毫不夸张的说, 21 世纪谁拥有了一流的人 才, 谁能让一流的人才产生超一流的效益, 谁就会在激烈 的市场竞争只胜出。

没有人哪个领导者再怀疑人才的重要性, 但不是每个 管理者都明白如何才能留住人才, 并能让他们快快乐乐, 尽心尽力地为公司效力。更少的管理者知道如何让每个员 工都变成人才一一在自己本职岗位上做出卓越的贡献。

鉴于人是企业的首要资源, 人的管理问题也应该是管 理学的核心问题。探索人的心理活动, 通过激励人心的各 种途径和技巧, 从内部点燃员工的激情, 来最大限度的提 高效率也成了十分重要的课题, 这正是管理心理学研究的 内容。管理心理学立足与人本思想, 以有别与传统的管理 方法, 从心理学的角度来探讨对人的管理问题。

\section{2. 激励是人本管理的核心}

激励是管理心理学上一个非常重要的功能, 是管理心 理学的核心问题, 也是管理心理学研究的热点问题之一。 激励就是调动人的积极性的过程。激励大师金克拉曾说: “你若想成为人群中的一股力量, 便必须掌握激励, 生活 就是这样, 你把它放入自己所处的人际中, 人们就记得你 信任你, 就像黑夜相信灯光一样。”研究管理心理学, 主 要目的就是为了掌握个体与群体的心理, 激发每个人的积 极性，做到人尽其才。

下面结合具体案例及本人经验来讨论一下激励的方 式。主要有目标激励, 期望激励, 责任激励, 危机激励, 奖励激励。

\section{1 目标激励}

目标激励可以包括成就激励, 自我实现激励, 或者前 景激励。目标是一种刺激, 合适的目标能诱发人的动机, 进而促使达成目标。

人的动机来源于需要, 而需要的满足便是人活动的最 大动力。管理者的工作就是如何巧妙地将企业的目标与个 人的需要统一起来。即目标的设置问题。管理者向员工描 绘一个愿景, 并能鼓动员工看到这个愿景对自己的价值, 并热情主动地去实现它, 这就是一个成功的目标。一个很 好的办法是让员工参与到目标的制定过程中去。这样他们 就会以一种主人公的, 积极的态度来向目标努力, 目标真 地实现了, 他们就会有一种成就感, 一种莫大的心理满足。 假使只是一味给他们灌输愿景而不给他们机会去提意见 或者进行批评, 他们很可能不愿接受甚至反对你的规划, 而一旦有了他们自己的参与, 他们就会有一种强烈的主体 意识。

从这个意义上说目标激励的本质就是自我实现激励, 成就激励。对一个渴望自我实现成就感强的人来说, 给他 提供一个能够充分展示自己, 具有一定挑战性的目标, 将 会产生强大的驱动力。

\section{2 期望激励}

这里讲的期望是指管理者对员工能力的一种评价, 并 通过一定的方式传递给员工。期望的基础是信任, 而信任 又是一种真诚的期望。因此也可把期望激励称为信任激 励。事实上, 人都是渴望认同渴望得到别人的尊敬的。如 果人们知道我们对他们有很好的期盼, 大部分情况是, 他 们会尽全力去符合我们的期盼, 如果我们总是期盼最差 的, 他们的表现就会真的令人失望。信任是一种动力, 一 句: “我相信你能行! ” 就能让人热血沸腾。有时候人并 不知道或者不相信自己深埋着的潜力, 需要聪明的管理者 去唤醒它。

当你总是从员工那里期望最好时, 无意中, 你的言调、 表情、态度都会传达出你对他们的这种期许, 这是信任的 激励。在要求员工时, 管理者的期望应略高于员工表现出 来的能力, 这样即使任务具有一定的挑战性, 激发员工的 成就心理, 又能使员工的感到上级的信任与认可, 从而充 分发挥潜能, 还能避免按部就班消磨员工意志, 又达到了 提高效率的目的, 可以说是一举三得。相反, 若是大材小 用, 则会传达出消极的信息。实质上是一种负激励。有实 验就发现, 看大门, 本科生比不上初中生。所以管理者对 员工的期许是一种关键的激励方法。 


\section{3 责任激励}

员工既然来到公司, 承担一份工作就对公司, 对自己 承担了一份责任, 这是员工在进公司之初, 管理者就应该 向他们传达的信息。否则公司就是一盘散沙，公司将没有 任何凝聚力。向员工灌输责任的重要性, 那么责任就是 对员工的激励。每名员工都要尽量完成自己的职责。

责任激励的实施需要员工有较高的素质, 也要以公司 有公开透明的管理制度，充分的个人发展空间做基础。

\section{4 危机激励}

危机激励, 又可称为竞争激励。在现代市场经济条件 下，优胜劣汰，适者生存是铁打的规律。面对这样一种弱 肉强食的残酷竞争机制任何企业都必须力争上游, 否则就 只有死路一条。事实上 30 年前的世界 500 强企业有三分 之一都已经销声匿迹。现代企业的平均寿命只有 40 岁, 比人的还短, 足见竞争之激烈。只有引入竞争, 承认竞争, 敢于竞争, 并用竞争去激励自己的员工, 才能使企业活力 四射，永葆生机。

\section{5 奖励激励}

以上各种激励方式最终都要通过奖励优秀来强化与 肯定，否则激励就成了空头口号，难以达到激励的效果。 有实验证明，人在无激励状态下，仅能发挥潜力的 10\%-30\%，在物质奖励作用下，能发挥自身潜力的 $50 \%-80 \%$ ，在适当的精神激励下，可发挥潜能的 80\%-100\%。

一定要对最好的员工施以奖励, 这是企业价值观的表 现。若得当，将会形成一种崇尚先进，争当先进的良好风 气; 若不得当, 则真正有成就有才能的人的积极性就会被 打消, 最后要么走人, 要么像那些不思进取的人一样得过 且过。

实施奖励时有以下几点要注意:

（1）奖励要公平 公平是奖励的第一要素。人们 总是要将自己所做的贡献和所得的报酬和一个自己条件 相当的人做比较, 如果这两者相当, 双方都会有公平感, 否则, 即使奖励很重, 仍会引起不满。最后一课的案例中, 小刘和小李的案例就是一个明显的有失公平的奖励, 这令 小刘的积极性受到很大打击。

（2）奖励要及时奖励若不及时，会让人有接受 空头支票的感觉。在等待奖励的时间里，员工会表现的焦 躁不安, 工作积极性受到明显影响。唐代著名政治家柳宗
元有言： “赏务速而后有劝。” 意思就是, 奖赏只有及时 实现, 才能达到勉励的效果。

（3）物质奖励精神奖励并重, 按需激励 管理者 应根据不同人的性格和需求特点来进行因人而异的奖励。 马斯洛的需要层次理论指出,不同人群的主要需求是不同 的。一般来说在经济水平欠发达的地区，奖金等物质奖励 有较好激励效果, 而在生活水平较高的地区, 荣誉精神享 受就更加重要。

总之，企业的管理者在面对日趋激烈的市场竞争时， 必须不断构思新的激励方案, 使激励的形式别开生面, 富 有新鲜感能打动人, 才能以相同的代价取得更大的效果。

\section{3. 企业文化是长期激励机制的根本}

无论哪种激励方式, 若只是单独对一人一事, 而不营 造一种氛围, 不形成一种制度, 都只能是一时的激励。学 习创造，积极向上，追求卓越，富有自身特色的企业文化 才是长期激励机制的保证。作为企业的一项重要软实力, 企业文化被誉为是现代企业的灵魂。它是衡量一个企业的 凝聚力, 内涵和发展潜力的一项关键指标。没有企业文化 的公司最多风光一时, 绝不会持久。经营管理策略可以模 仿, 人才也可以买到, 但企业文化是模仿不来的, 这也是 企业最宝贵的财富。一个人人比学习, 人人争创造的企业 会有无穷的战斗力，会让人才有一种如鱼得水的感慨。

美国哈佛大学的一位教授曾指出: “只要你是成功者, 你就会有一种企业文化, 而没有企业文化的企业是那些长 期以来一直失败的企业。”美国《财富》杂志在谈到世界 上最受推崇的公司时说: “拥有自创文化的公司可以不受 经济萧条的影响。”

企业文化对企业的长期经营业绩具有重大影响。一种 强大的有生命力的企业文化，事实上就是一种激励企业不 断进步, 员工不断成长的文化。这种文化不是靠一时的规 章制度所能建立的，它靠的是长期的积淀。

总之, 管理心理科学在企业管理中的作用无处不在, 意义重大。现代的领导和企业管理者比以往任何时候都更 需要具备良好的心理素质去把眼光投向世界, 投向整个国 际市场, 以便面向国际市场实现企业高效运转。他们也必 须使他的员工具备良好的心理素质。换言之，一个有效的 现代企业管理者, 必须重视心理科学的运用, 心理科学的 运用也必将会给企业带来高效率的管理。而每一个员工具 备了良好的心态，才能适应改革大潮的需要。 


\section{参考文献(References)}

[1] Kong Xiangyong, "management psychology," Higher Education Press, 2001 first edition

[2] (US) Stephen P - Robbins. "Management science", Renmin University of China press, Fourth

[3] "Pinnacle of humanistic management: activation of human resources", Chinese material press, 2004 November.
[4] Yang Jingzong. One hundred thousand how do professional managers how to build the core competitiveness of enterprises, Peking University press, 2004

[5] Wangpu. The how to make your enterprise evergreen leader of enterprise core competitiveness analysis ", Beijing University Press, 2006 April

[6] (United States) Peter Deruk, "the highly productive manager", the mechanical industry press, June, 2006 